TITLE:

\title{
SYMPODOMMA HATAGUMOANA SP. NOV., A NEW CUMACEA FROM SAGAMI BAY
}

\author{
$\operatorname{AUTHOR}(\mathrm{S})$ : \\ Gamo, Sigeo
}

\section{CITATION:}

Gamo, Sigeo. SYMPODOMMA HATAGUMOANA SP. NOV., A NEW CUMACEA FROM SAGAMI BAY. PUBLICATIONS OF THE SETO MARINE BIOLOGICAL LABORATORY 1969, 17(3): 175182

ISSUE DATE:

1969-11-29

URL:

http://hdl.handle.net/2433/175594

RIGHT: 


\title{
SYMPODOMMA HATAGUMOANA SP. NOV., A NEW CUMACEA FROM SAGAMI BAY
}

\author{
Sigeo GAMÔ
}

Faculty of Education, Yokohama National University, Yokohama

With 4 Text-figures

The author had an opportunity to examine a small material of cumacean Crustacea collected by His Majesty's Research Vessel "Hatagumo" in Sagami Bay. He would like to express his appreciation to Dr. Tune SAKaI who kindly offered the specimens to the author for taxonomical study.

The collection contains the following six species:-

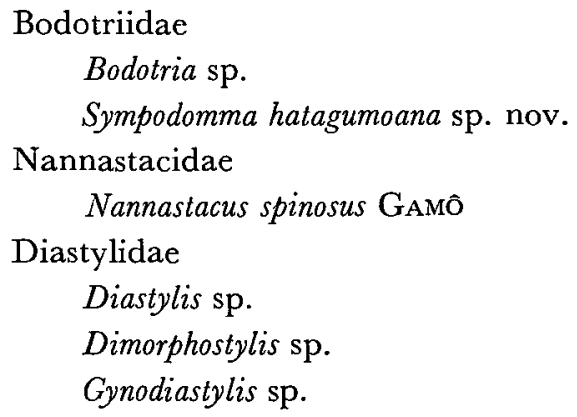

In the present paper Sympodomma hatagumoana sp. nov. is described as a new species. Two immature specimens of this new species were available. Unfortunately, however, they were both heavily injured at different body parts, and therefore the description of the species was composed of the observations made on the two specimens. The types will be deposited in the Biological Laboratory of the Imperial Household.

\section{Sympodomma hatagumoana sp. nov.}

(Figs. 1-4)

Two immature male specimens, both about $14.3 \mathrm{~mm}$ long, are partly heavily injured (Fig. 1). In the holotype (BLIH reg. no. 2230) the free thoracic segments, the abdomen and uropods are damaged, while in the paratype (BLIH reg. no. 2223) the dorsal part of the carapace is crushed. The latter was dissected to examine the

Publ. Seto Mar. Biol. Lab., XVII (3), 175-182, 1969. (Article 8) 


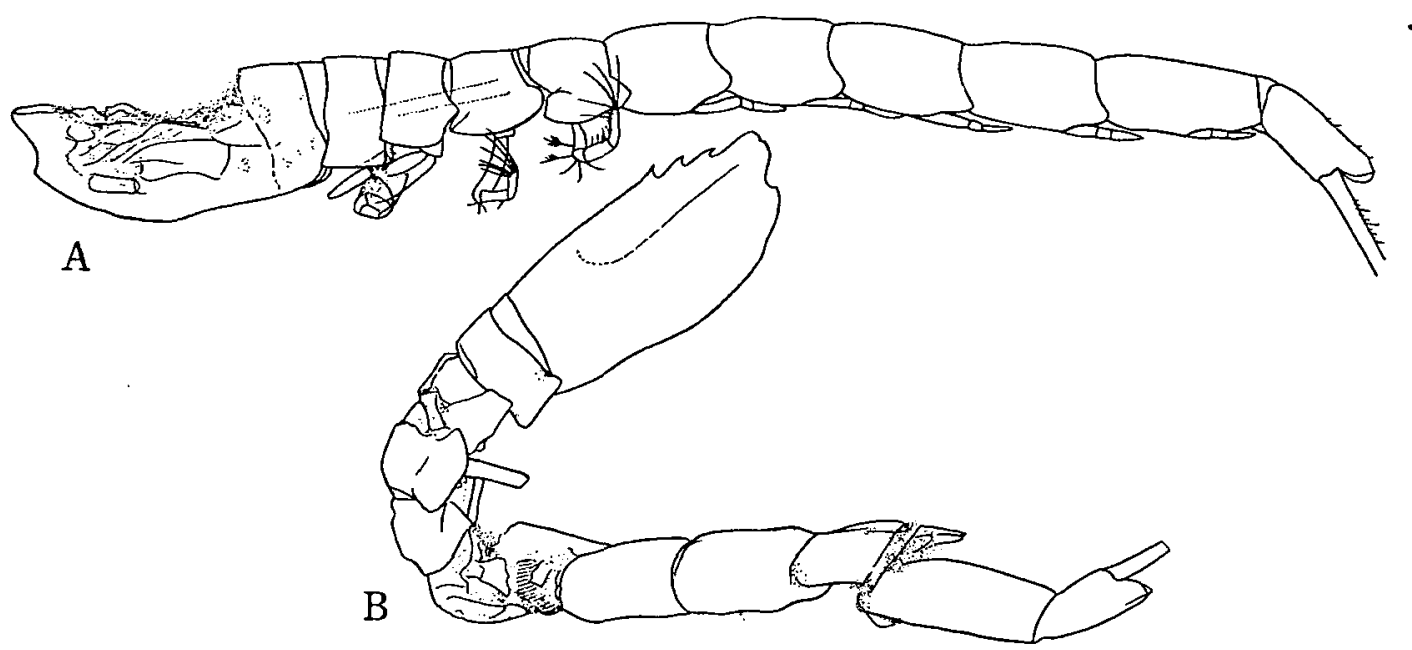

Fig. 1. Sympodomma hatagumoana sp. nov,, outline of two immature male specimens. both about $14.3 \mathrm{~mm}$ long. A: paratype (BLIH reg. no. 2223). B: holotype (BLIH reg. no. 2230).

mouth parts and other appendages.

The carapace (Fig. 2, A, B) is a little less than one-fourth of the total body length and about twice as long as the depth which is a little larger than the width. There are no spaced round tubercles nor papillose structure on the entire surface. The dorso-median carina is very prominent on the frontal lobe and cut into three teeth pointed forward. The posterior portion of the dorso-median carina is well marked, but without any tuberculations. The antennal notch is widely concave, rather deep, with round antero-lateral corner. The lateral or lower margin is serrate (Fig. 2, G). The ocular lobe is digitiform and extended slightly beyond the apex of the pseudorostral lobes.

The length of the free thoracic segments together is nearly as long as the carapace. The second to fifth segments are posteriorly slightly narrowed and moderately dimnished in depth. The postero-dorsal margin of the last three segments is setose. The side plates are very prominent. The antero-lateral angle of the fourth side plate is much protruded anteriorly. The sternites of the first and fourth free thoracic segments have each a median ventral spine pointed forwards. The fifth bears a median ventral swelling with a short spine. The sternite surface between the bases of the third maxillipeds is also provided with a swelling with four short spines (Fig. 2, $\mathrm{G}$ and $\mathrm{H}$ ).

The abdomen is a little longer than two and half times the free thoracic segments together and is provided with five pairs of rudimentary pleopods. The first two abdominal segments are approximately of the same size and each a little shorter than the third or the fourth segment. The postero-dorsal margin of the first four segments is fringed with setae and their postero-lateral portion is much produced backwards. 


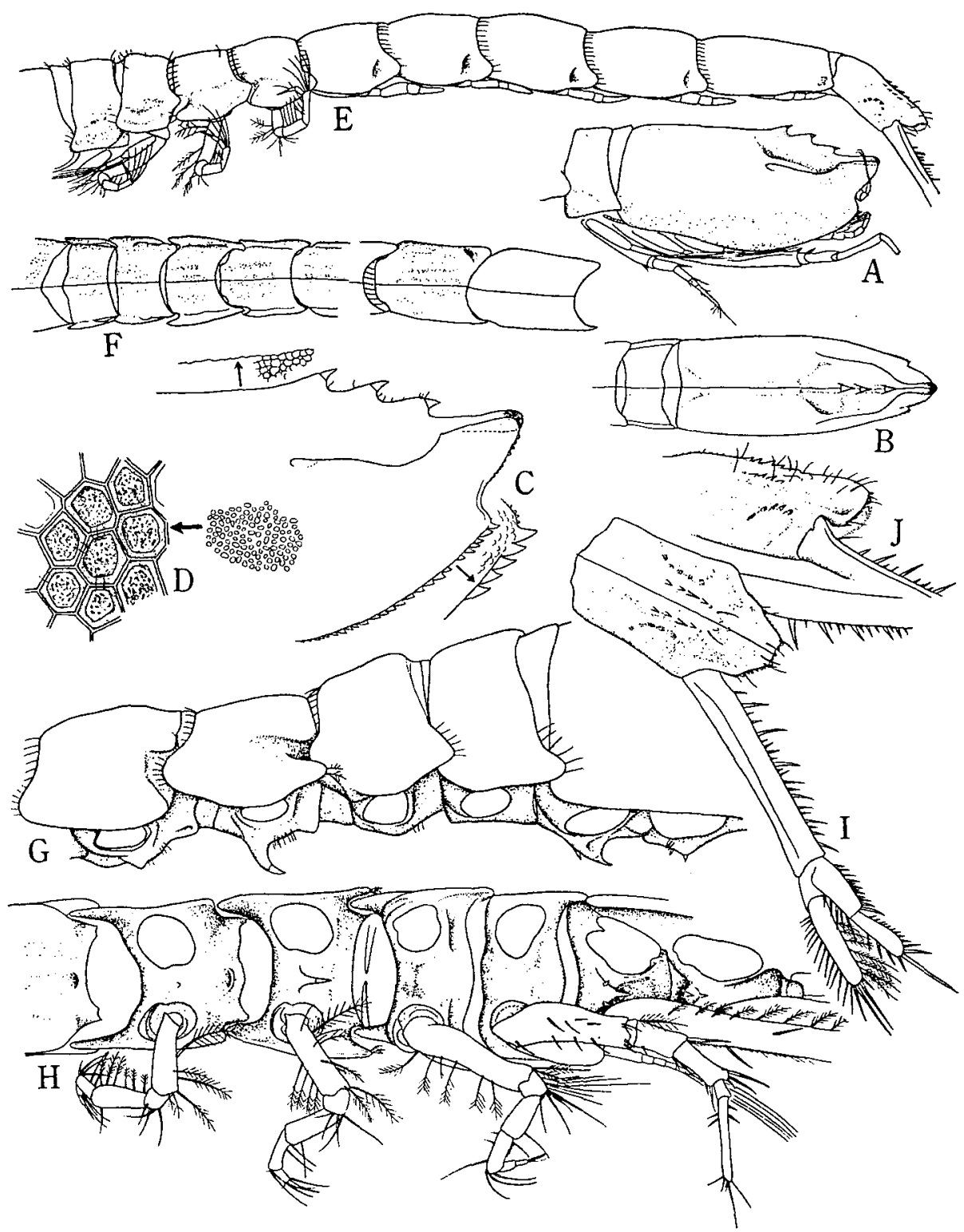

Fig. 2. Sympodomma hatagumoana sp. nov., immature males. A: anterior portion of body, lateral view. B: anterior portion of body, dorsal. C: anterior portion of carapace, lateral. D: integumentary sculpture on carapace surface. E: posterior portion of body, lateral. $F$ : thoracic portion and first three abdominal segments, dorsal. G-H: thoracic portion of body, lateral $(\mathrm{G})$ and ventral $(\mathrm{H})$ view (right thoracic appendages are removed). I : last abdominal segment with uropods. J: last abdominal segment, lateral. (A-D: holotype; E-J: paratype). 
The fifth segment is the longest, nearly one and one-fifth times as long as the fourth. The last segment (Fig. 2, I and J) is a little longer than three-fourths of the fifth and bears a dorso-median swelling furnished with six pairs of spines and some short setae. The posterior portion is extended between the bases of the uropods to form a broad lobe, the posterior margin of which is serrate and with about four pairs of short setae. The dorso-median and dorso-lateral carinae of the free thoracic and abdominal segments are very like those in $S$. diomedeae (Calman).

The first segment of the antennular peduncle is about two-thirds of the combined length of the two subequal distal segments (Fig. 4, A). The main flagellum is rather small, two-segmented, with a small segment-like protuberance, and carries tow long subequal aesthetascs. The accessory flagellum is nearly half as long as the main flagellum and consists of two segments.

The left mandible bears a lacinia mobilis and 23 plumose setae on the inner border (Fig. 3, B).

The maxillula and maxilla are shown in Fig. 3, C and D.

The first maxilliped bears 17 branchial leaflets and an accessory one on the branchial apparatus (Fig. 3, E).

The second maxilliped is shown in Fig. 3, F.

The basis of the third maxilliped (Fig. 4, B) is very elongate and a little less than two and two-thirds times the length of the remaining distal segments together. The inner border is hairy and serrate. The outer distal angle is produced into a broad lobe reaching the level of the middle of the merus. The ischium is much longer than wide, nearly as long as the merus but a little shorter than the carpus. The merus bears several denticules on the outer distal margin.

The basis of the first peraeopod (Fig. 4, D) is rather slender, less than the combined length of the ischium, merus, carpus and propodus, thickly hairy on the inner and serrate on both borders. It is provided with three spines in the middle portion and two spines and serrations on the distal end. The ischium is one-half as long as the merus and with a stout tooth at the inner distal angle. The propodus is nearly subequal to the combined length of the merus and carpus. The distal portion of the dactylus is missing.

The basis of the second peraeopod (Fig. 4, F) is nearly three-fourths as long as the distal segments together and is armed with five spines along the inner and with three spines along the outer lateral borders. The ischium is very short, but distinct. The merus is a little shorter than the carpus, both segments are armed with five and four spines respectively. The dactylus is slender, longer than the propodus and carpus combined together and carries four lateral spines in the proximal portion and six setae of different length at the apex. One of the distal setae is very long, nearly equal to the dactylus.

The third peraeopod (Fig. 4, G) is nearly four-fifths as long as the second. The basis is a little shorter than the distal segments together. 


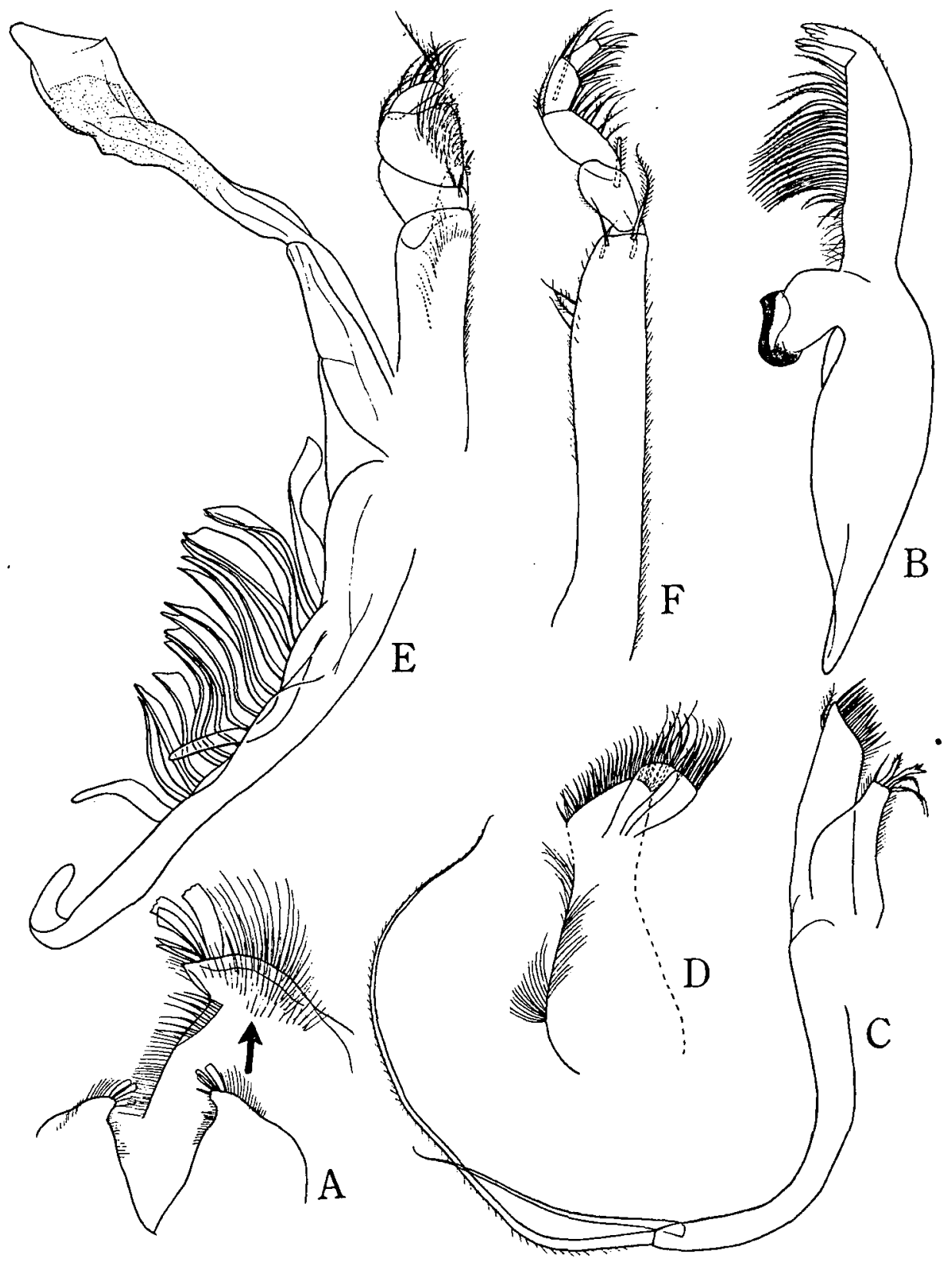

Fig. 3. Sympodomma hatagumoana sp. nov., immature male paratype. A: labium. B: left mandible. C: maxillula. D: maxilla. E-F : first $(E)$ and second $(F)$ maxillipeds. 
The fourth peraeopod (Fig. 4, H) is a little shorter than the third; its basis is less than two-thirds of the combined length of the distal segments. The fifth peraeopod (Fig. 4, I) is much shorter than the fourth; the basis is nearly half as long as the distal segments together. The integumentary texture on the segments surface of the first two pairs of the peraeopods is shown in Fig. 4, E and that of other peraeopod is shown in Fig. 4, J. The first three pairs of the peraeopods are provided with well developed exopods.

The peduncle of the uropod (Fig. 2, I) is slightly longer than the last abdominal segment and is armed with twenty-one spines of variable sizes on the inner border. Both rami are subequal in length and each a little longer than one-half of the peduncle. The exopod bears seven plumose setae on the inner border, fourteen spines on the outer border, and four spines at the apex, the middle two of the four are rather long. The endopod is two-segmented. The proximal segment is nearly subequal to the distal one in length and bears twelve unequal spines on the inner and five on the outer border. The distal segment carries nine spines on the inner border, four on the outer border, and three at the distal end, the middle of the three is very long, nearly as long as the distal segment.

Material: 1 ot immature, holotype, B.L.I.H. reg. no. 2230, with distal portion of the first peraeopod and the distal part of both uropods detached. The third free thoracic, first and fourth abdominal segments broken. 1 t immature, paratype, B.L.I.H. reg. no. 2223, lacking the distal portion of the distal segment of the first pair of peraeopods. The carapace is broken. About $5 \mathrm{~km}$ southwest-by-west off Jo-ga-shima, $300 \mathrm{~m}$ deep; March 13, 1964.

Remarks: This species is very closely allied to S. diomedeae (Calman) (Galman, 1912) and S. africana Stebbing (Stebbing, 1912). According to Hale (1944) and Harada (1964) the dorsal crest of the carapace cut into three teeth and the rounded or papillose tubercles scattered on the carapace, both features are well-defined in the female and immature male, may become almost obscure in the fully adult male (17 mm long) of $S$. diomedeae. The latter are missing all over the carapace but on the anterior portion of the pseudorostrum which is still furnished with less prominent papillose tubercles. In the immature male $(14.3 \mathrm{~mm}$ long) of the present new species, however, the carapace is provided with a well-marked dorsal crest with three teeth but without any trace of round or papillose tubercles all over the surface. The new species has a median ventral spine on the sternite of the third (the thoracic segment with the third maxillipeds), fourth and seven (the first and fourth free) thoracic segments, whereas $S$. diomedeae has a median ventral spine on the sternite of the sixth and seventh thoracic segments in the nuptial and immature males but a spine only on the seventh thoracic sternite in the female.

The new species is distinguishable from $S$. diomedeae by the above-mentioned differences and from $S$. africana by that the first segment of the endopod of the uropod is about as long as the second in the new species. 


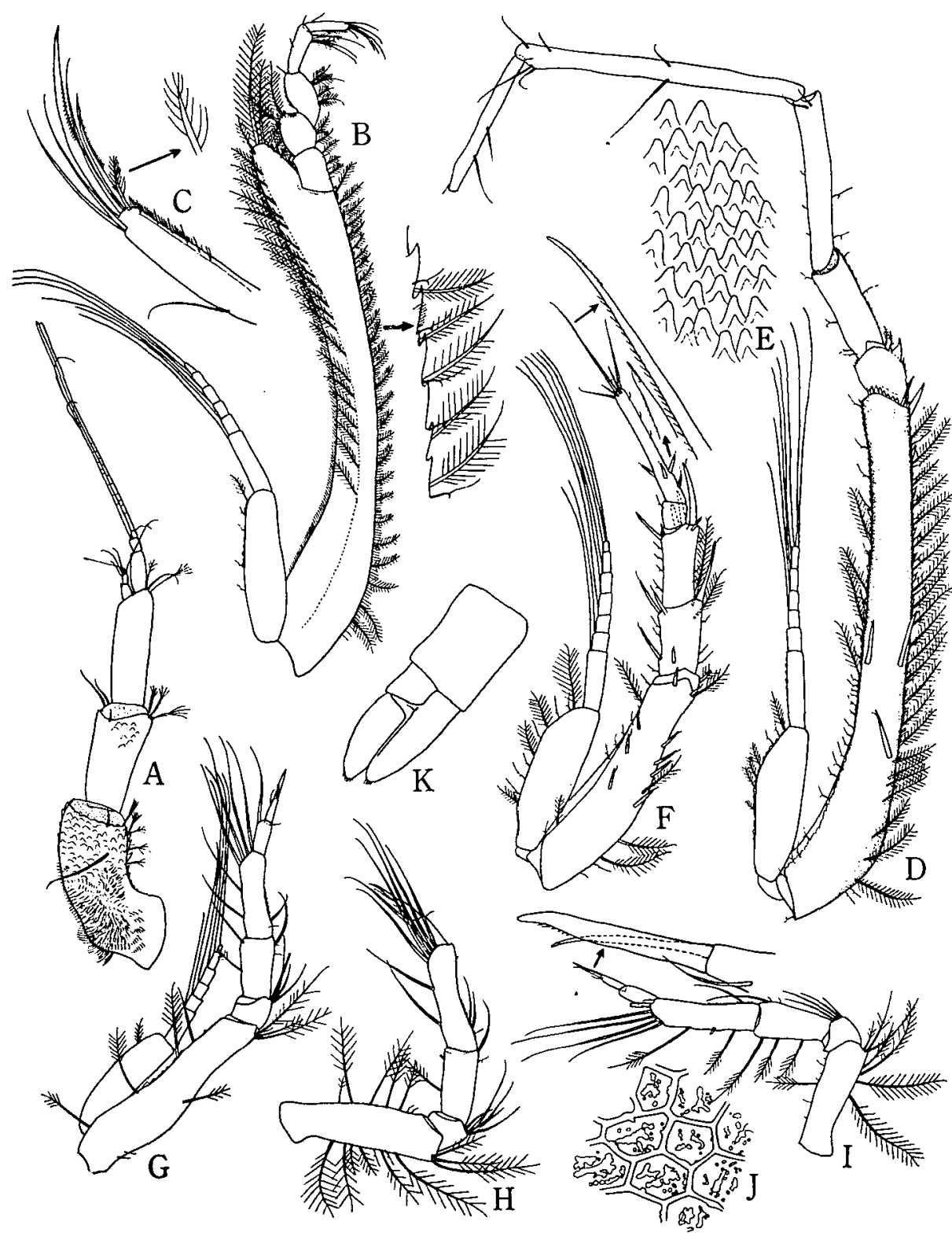

Fig. 4. Sympodomma hatagumoana sp. nov., immature males. A: antennule. B: third maxilliped. C: dactylus of third maxilliped. D: first peraeopod. E: integumentary sculpture on segments surface of first peraeopod. F-I: second (F) to fifth (I) peraeopods. J: integumentary sculpture on segments surface of fifth peraeopod. K: second pleopod. (A-C, E-K: paratype; D: holotype). 


\section{ITERATURE}

Calman, W.T. 1912. The Crustacea of the order Cumacea in the collection of the United States National Museum. Proc. U.S. Nat. Mus., vol. 41, pp. 603-676, 112 figs.

FaGe, L. 1951. Les Cumacés. Faune de France. T. 54, pp. 1-136, 109 figs., Paul Lechevalier, Paris.

Gamó, S. 1967-1968. Studies on the Cumacea (Crustacea, Malacostraca) of Japan. Part I-III. Publ. Seto Mar. Biol. Lab., vol. 15, pp. 133-163, 11 figs.; pp. 245-271, 10 figs.; vol. 16, pp. 147192, pl. 18 (coloured), 15 figs.

Hale, H.M. 1944. Australian Cumacea. No. 8. The family Bodotriidae. Trans. roy. Soc. S. Aust., vol. 68 , pp. 225-285, 38 figs.

1949. Australian Cumacea. No. 15. The family Bodotriidae (cont.). Rec. S. Aust. Mus., vol. 9, pp. 107-125, 9 figs.

Harada, I. 1963. On the developmental stages of Cumacea. Zool. Mag. Tokyo., (Proc. thirtyfourth annual meeting of Zool. Soc. Japan). vol. 72, pp. 322-323. (In Japanese)

1964. Cumacean fauna of Japan. III. Family Bodotriidae Pt. 1. Genus Heterocuma Mrers and Sympodomma Srebiinc. Jap. Journ. Zool., vol. 14, pp. 97-104, 3 pls.

Jones, N.S. 1963. The marine fauna of the New Zealand: Crustaceans of the order Cumacea. Bull. N.Z. Dep. Sci. industr. Res. 152, pp. 1-80, 349 figs. (N.Z. Oceanogr. Inst. Mem. No. 23).

Kurian, C.V. 1954. Notes on Cumacea (Sympoda) in the Zoological Survey of India. Rec. Ind. Mus., vol. 52, pp. 275-311, 14 figs.

Stebing, TH. R.R. 1912. The Sympoda. Ann. S. Afr. Mus., vol. 10, pp. 129-176, 16 pls. 1913. Cumacea (Sympoda). Das Tierreich. Lief. 39, pp. i-xvi, 1-210, 137 figs., Berlin.

Zimmer, C. 1921. Einige neue und weniger bekante Cumaceen des Schwedischen Reichsmuseums. Ark. Zool., Bd. 13, nr. 21, pp. 1-9, 6 figs.

1941. Cumacea. In: Bronn's Klassen u. Ordnungen des Tierreich. Bd. 5, Abt. 1, pp. 1-222, 226 figs. Akad. Verlangs. Leipzig. 